University of Nebraska - Lincoln

DigitalCommons@University of Nebraska - Lincoln

Faculty Publications, Department of Psychology

Psychology, Department of

3-9-1998

Predictors of Children's Risk Appraisals

David DiLillo

Oklahoma State University, ddilillo@unl.edu

Richard Potts

Oklahoma State University

Susan Himes

Oklahoma State University

Follow this and additional works at: https://digitalcommons.unl.edu/psychfacpub

Part of the Psychiatry and Psychology Commons

DiLillo, David; Potts, Richard; and Himes, Susan, "Predictors of Children's Risk Appraisals" (1998). Faculty Publications, Department of Psychology. 203.

https://digitalcommons.unl.edu/psychfacpub/203

This Article is brought to you for free and open access by the Psychology, Department of at DigitalCommons@University of Nebraska - Lincoln. It has been accepted for inclusion in Faculty Publications, Department of Psychology by an authorized administrator of DigitalCommons@University of Nebraska - Lincoln. 


\title{
Predictors of Children's Risk Appraisals
}

\author{
David DiLillo, Richard Potts, and Susan Himes \\ Oklahoma State University
}

\begin{abstract}
This study explored variables associated with cognitive appraisals of physical risk in a sample of 62 elementary school children. Participants were presented with drawings of persons in three categories of risky situations typical of children, typical of adults, and typical of television plots. They were asked to judge the potential for physical injury in each. Results indicated that children tended to appraise risks in child, adult, and TV-plot risk situations differently, and that each type of situation was predicted by different variables. For the child situations, greater amounts of direct experience with the risk situation itself was found to be associated with lower risk appraisals. Appraisals of adult risk situations were predicted by age, with older children reporting lower risk appraisals. Sensation seeking, injury history, and weekday cartoon viewing all predicted lower risk appraisals of television situations. Implications of these findings for knowledge about the origins of childhood injury are discussed.
\end{abstract}

Unintentional injury has been cited as the leading cause of death each year among children between one and 19 years of age (Rodriguez, 1990). The personal and financial costs of childhood injury and disability are devastating. Each year 600,000 children are hospitalized, 16 million receive emergency care, and 30,000 suffer permanent disability as a result of unintentional injury (Rodriguez, 1990). The estimated financial cost of injury and disability in the U.S. is $\$ 158$ billion annually (Rice \& Mackenzie, 1989). Figures such as these prompted the National Academy of Sciences to conclude that "injury is the principle public health problem in America today; it affects primarily the young and will touch one of every three Americans this year" (National Academy of Sciences, 1985, p. v).

Despite the magnitude of the problem and repeated calls for additional research (e.g., Spielberger \& Frank, 1992; Routh, 1997), relatively few studies have explored potential behavioral and psychological mechanisms that may underlie children's unintentional injuries. Particularly understudied has been children's internal processing of physically risky situations. For instance, antecedent affective and cognitive responses to physical risks may impact the extent to which injury occurs. In the face of potentially dangerous situations, these reactions may influence children's decisions whether to take risks that could 
lead to injury. Evidence supporting this possibility comes from correlational data examining relationships between children's self-reported emotional responses to various kinds of risk and their actual risk behaviors (Miller \& Byrnes, 1997). Specific to injury, children who report a sense of exhilaration in response to physical risks have been found to take more actual physical risks than those who respond to risks with fear (Cook, Peterson, \& DiLillo [in press]). Cognitive and emotional reactions to risks may play an even larger role in the injury process with increasing age, as children begin spending more time in unsupervised situations. Although the exact relationship between risk appraisals and injuries has not yet been fully elucidated, these variables may well be associated in ways important to the understanding of unintentional injury.

\section{Developmental Issues}

A small number of studies have investigated developmental patterns in children's judgments of risk situations. In an early investigation, Walesa (1977) assessed the risk perceptions of 6-18 year-olds who were shown pictures of various categories of hazardous and neutral situations and asked to predict what would happen next. Children's risk perceptions of danger tended to follow a U-shaped curve, decreasing steadily until the age of eight, then increasing again around age 11. More recent examinations of developmental patterns of expected injury consequences suggest a more steady decline with increased age. In a study of second- fourth-, and sixth-grade children and college students' responses to a simulated bicycle injury event, younger children expected greater injury and experienced more fear than older subjects, regardless of the specific outcome of the collision (Peterson, Gillies, Cook, Schick, \& Little, 1994). In a follow-up study that included a broader age range of subjects, younger participants again expected more fear and less exhilaration than older participants (Peterson, Brazeal, Oliver, \& Bull, 1997). Thus, while data has consistently shown a trend for risk appraisals to decrease linearly through middle childhood, less consistency has been found in patterns of risk appraisal in late childhood and adolescence. These age-related differences in appraisal may be largely a function of prior experiences with injury and risk, as well as children's numerous emerging capabilities, including cognitive and information processing skills, visual-spatial abilities, social competencies, emotional control, and self-regulatory tendencies (Hyson \& Bollin, 1990).

\section{Model of Risk Appraisal}

Investigators have yet to explore the potential range of influences upon children's cognitive appraisals of physical risks. Hyson and Bollin (1990) have proposed a conceptual model that provides a useful starting point for examining such factors. Conceptualizing risk appraisal as including both cognitive and affective influences upon a child's perceived probability of harm in a given situation, their model outlines a variety of factors that may impact these perceptions. The present study explores the relationship between several of these factors, extends their model to include children's own risk experiences, and relates all of these to children's cognitive appraisals of risk. Specifically, children's television viewing patterns, sensation-seeking dispositions, current risk-taking behavior, past injury history, and age, were examined as possible correlates of risk appraisal. 
Television. A significant source of socialization for children and adults is television programming (Huston et al., 1992). Although the impact of TV on many interpersonal behaviors has been studied extensively, as in the case of aggressive behavior, its role in injury behaviors has been examined only in a small number of investigations. Adults report that they learn about many injury-producing hazards primarily from the television media (Slavic, 1987). Especially relevant to the present study is the finding that children's television programming depicts a multitude of injury-related behaviors that rarely result in negative consequences such as severe pain or lasting impairment (Potts \& Henderson, 1991). From a social cognitive perspective (Bandura, 1986), observation of television models who engage in risky behavior that results in few negative consequences may lead children to expect that similar situations in everyday life have little physical risk. Empirically, it has been shown that exposure to risky TV content increases children's self-reported willingness to take risks (Potts, Doppler, \& Hernandez, 1994) although the effects of TV on risk appraisals has not been studied specifically. In this study, children's television viewing patterns were examined as possible correlates of risk appraisal.

Relevant Personality Characteristics. Sensation seeking, an attraction to varied, novel, and complex experiences, has been linked repeatedly to risk appraisal and risky behaviors in adults (Zuckerman, 1979). Adult sensation seekers take more physical risks (including skydiving, skiing, mountain climbing, and high-speed driving), and tend to judge many behaviors to be less risky than do sensation avoiders (Horvath \& Zuckerman, 1993; Zuckerman, 1979; Zuckerman, 1994). Previous research has supported the existence of a sensation seeking construct for children (e.g., Russo et al., 1991; Russo et al., 1993). Among kindergarten and school-aged children, sensation seeking has been associated with a preference for physically risky activities and complex activities such as puzzles (Kafry, 1982). Sensation seeking has also been found to predict self-reports of risk taking for children between six and nine years of age (Potts, Martinez, \& Dedmon, 1995). Despite these efforts, the association between sensation seeking and risk appraisal in child populations has not been studied and will be investigated here.

Injury History. No consensus exists regarding the exact relationship between past injuries and the likelihood of future injury. Some experts (e.g., Valsiner, 1985) maintain that knowledge gained from early injury experiences serves to protect children from similar injuries later. There is little firm evidence to support this assertion, however. In fact, children with a previous history of unintentional injury have been found to be at significantly greater risk of later injury (Jaquess \& Finney, 1994). It has been suggested that the preventive value of early injury experiences may be reduced due to victims' and caregivers' beliefs that injuries are a product of atypical circumstances and thus are unlikely to recur (Peterson, Moreno, \& Harbeck-Weber, 1993). Extrapolating from this literature, it seems logical to conclude that experiencing risk in the absence of serious injury may have a desensitizing effect upon children, resulting in lower risk appraisals and perhaps increasing the likelihood of subsequent injuries. This study provides a preliminary examination of children's injury history and their current appraisals of risks.

Personal Experience with Risk. Typically, conceptualizations of risk appraisals have encompassed various types of risks including natural hazards, traffic dangers, and abuse by adults (e.g., Hyson \& Bollin, 1990). However, according to social cognitive princi- 
ples (Bandura, 1986), it can be argued that knowledge about risk (i.e., the probable consequences of a behavior) is acquired in a situation-specific or behavior-specific manner, based in part upon the one's personal experience with a particular risk situation. Support for this proposal comes from studies of adults' perceptions of risk, which found variability even within single hazard domains such as automobile accident scenarios (Slavic, MacGregor, \& Krauss, 1987, as cited in Slavic, 1987). To explore the possibility that children's risk appraisals may show similar specificity, participants in this study were asked to appraise three categories of physical risks. It was reasoned that estimations of injury probability and the factors influencing those estimates would differ in general accordance with the amount of direct experience children had with a given risk situation. Thus, three categories, or domains, of risk situation were used. The first domain included risky activities commonly experienced by most children (e.g., jumping out of a moving swing or swimming in a pool). The second domain was comprised of adult risk behaviors and included situations few children had experienced first-hand, yet are relatively common in the "real world" (e.g., using a blowtorch or working underneath a car). Finally, a television domain included risky situations likely to have been experienced by children only vicariously through television viewing (e.g., jumping from the roof of one building to another or scuba diving). Thus, children judged several risk situations that varied in terms of likelihood of direct personal experience.

Summary. Based upon previous research the following hypotheses were formulated regarding the association between risk appraisal and the independent variables included in this study. First, social learning principles suggest that an inverse relationship might be expected between the amount of television viewed and children's risk appraisals. That is, the more television viewed (particularly of shows like cartoons, which depict many injury-relevant behaviors), the lower risk appraisals are likely to be. This relationship was expected to be strongest between risk appraisal and television-specific risk scenarios. Second, previous findings showed that sensation seeking and risk appraisal are negatively correlated in adults (Horvath \& Zuckerman, 1993). Similar results were expected in the present child sample. Finally, it was expected that risk appraisals would decrease overall with age.

\section{METHOD}

\section{Subjects}

Sixty-two second and fourth grade children, 34 boys and 28 girls, participated in this study. They were recruited via parent consent letters from a public elementary school located in a small Midwestern town. The sample represented 53\% of those children solicited for participation. The age range of children chosen was from seven to ten years with a mean of $8.74(S D=1.09)$. This range represents the earliest ages at which children typically can legally be left alone without continuous adult supervision. Presumably, it is at this point that risk appraisals may begin to most strongly impact the injury process. Complete socioeconomic status data was provided by 49 of the participants from which the Hollingshead Two Factor Index (Hollingshead, 1957) was computed. Scores ranged from 21.0 to 60.5 with a mean of $37.29(S D=9.69)$. The majority of the children were Cauca- 
Table 1. Descriptions of Risk Appraisal Items

Description of item

\section{Child Domain}

1. Chasing a ball into the street

2. Swimming in deep water at a swimming pool

3. Throwing a lit firecracker

4. Shooting a slingshot at a can on a fence

5. Jumping out of a moving swing

Adult Domain

1. Making roof repairs on a two story house

2. Welding a piece of metal with a blowtorch

3. Working underneath an elevated car

4. Sharpening an ax on a grindstone

5. Sawing a tree with a chainsaw

\section{Television Domain}

1. Jumping from the roof of one high building to another

2. Circus performer swallowing a sword

3 . Being in a cage under water with sharks swimming nearby

4. Scuba diving near an underwater shipwreck

5. Swinging on a vine over a pit of fire

sian (95.2\%); 3.2\% were African American, and 1.6\% were Hispanic, reflecting the general ethnic and socioeconomic characteristics of the community.

\section{Materials}

Risk Appraisal Measure. Contained in Table 1 are descriptions of the 15 pictorial scenarios comprising the risk appraisal measure. To derive five scenarios for each of the three risk appraisal domains (child, adult, and television), a pool of 57 scenarios representing a variety of physically risky situations was generated by the investigators. Fiftysix undergraduate psychology students then classified each item as a situation most likely to be encountered by a typical child, by a typical adult, or typically only on a television program. From these results the live items with the most nominations for each domain were selected for the risk measure.

To measure risk appraisal, children rated the likelihood that the gender-neutral figure depicted in each of the 15 scenarios would be injured, using a five-point pictorial Likert scale ranging from 1 ("definitely will not get hurt") to 5 ("definitely will get hurt"). It has been shown that children of this age range can make probability estimates of the type described (e.g., Acredolo, O’Conner, Banks, \& Horobin, 1989).

Direct Experience Measure. To assess past direct experience with the 15 risk appraisal items, subjects were asked, upon completion of the risk appraisals, to designate which if any of the 15 behaviors they had actually engaged in, and to indicate on a 3-point scale $(0=$ never, $1=$ once, $2=$ more than once $)$ the frequency of those behaviors. Direct experience measures were the mean frequency scores within each risk domain. 
Television Viewing Questionnaire. Children's home viewing was assessed using a self-report questionnaire based upon procedures used successfully in the past by several investigators (e.g., Potts \& Martinez, 1994; Ross, Wartella, \& Lovelace, 1982: Tangney, 1988). Children were presented with 35 titles of television programs and asked to indicate their general viewing frequency for each program using a 3-point scale $(0=$ almost never, $1=$ sometimes, and $2=$ almost always). The programs were currently broadcast on two weekday afternoons, two weekday evenings, and Saturday mornings, and represented a variety of program categories defined in a program categorization scheme developed by the Center for Research on the Influences of Television on Children (1983). Based upon expected high levels of risky content five program categories were chosen for inclusion in the study. These included action/adventure shows, newscasts, weekday afternoon cartoons, Saturday morning cartoons, and sports programming. Scores used were the mean viewing levels of the programs within each category.

Sensation Seeking. This scale was derived from two sources: (a) Zuckerman's Sensation Seeking Scale for adults, Form V, Thrill and Adventure Seeking subscale (Zuckerman, 1979) and (b) modifications of the adult scales for use with child populations (e.g., Potts, Martinez, \& Dedmon, 1995; Russo et al., 1991). Ten pairs of 14 x $22 \mathrm{~cm}$ pictures were presented to subjects in a random order. Children chose the item in each pair in which they would prefer to participate. Each pair of items consisted of a sensation-seeking item (scored as 1) and a sensation avoiding item (scored as 0 ), the order of which was varied from item to item. The total sensation seeking score was the sum of all the item choices, and ranged from 0 to 10 . Sample items, with the sensation seeking alternative presented first, were: climbing high in a tree versus building a clubhouse beneath a tree, sledding down a hill versus building a snowman, riding an amusement park roller coaster that turns upside down versus a train that travels around an amusement park.

Injury Behavior Checklist. Parents of participants completed the Injury Behavior Checklist (IBC; Speltz, Gonzales, Sulzbacher, \& Quan, 1990), which has been found to be a valid and reliable predictor of child injury in both preschoolers (Speltz et al., 1990) and children ages six to nine (Potts, Martinez, Dedmon, Schwarz, DiLillo, \& Swisher, 1997). The instrument contains 24 items describing potentially injurious behaviors (e.g., "climbs on top of furniture," "leaves the yard without permission," and "takes chances on playground equipment"). Parents rated the frequency of those behaviors on a live point scale ranging from "not at all" (0) to "very often (more than once a week)" (4). The 24 items were summed to obtain a total score. This measure was included as an index of children's typical level of risky behavior.

Injury Frequency History and Demographics. Parents also completed a child injury history questionnaire which assessed lifetime frequencies of injuries experienced by their child, including broken bones, muscle strains, serious cuts, concussions, bums, poisonings, animal bites, insect stings/bites, water inhalation, shock, and other (miscellaneous). These were summed for an overall injury score. This questionnaire also included demographic items including parental marital status, education, and occupation, which were used to calculate the Hollingshead SES index (1957). 
Procedure. Each child participated in an individual interview session lasting approximately 30 minutes in an unused classroom during normal school hours. An adult experimenter read an introductory script, then administered, in random order, the measures described previously. Participants were then read a debriefing emphasizing safety awareness. All experimental procedures, including subject recruitment, complied with guidelines of the American Psychological Association (1992) and had been approved by the Human Participants Committee.

\section{RESULTS}

\section{Preliminary and Descriptive Analyses}

Cronbach's alphas for the independent measures were as follows: $\mathrm{IBC}=.89$, injury history questionnaire $=.73$, sensation seeking $=.72$, TV viewing questionnaire $=.81$. Coefficient alphas for the risk appraisal categories ranged from marginal (child $=.51$; adult $=$ $.58)$ to low $(\mathrm{TV}=.12)$. Original item groupings were maintained, however, because of the high interrater agreement among the undergraduates' conceptual categorizations of these items.

Means and standard deviations of independent measures were: sensation seeking $(M$ $=3.81, S D=2.49$; range $=0-10)$, total IBC scores $(M=17.50, S D=12.10$; range $=$ O$53)$, injury history $(M=1.45, S D=1.48$; range $=0-7)$, action TV shows $(M=.86, S D$ $=.42$; range $=0-1.65)$, sports $(M=1.06, S D=.57$; range $0-2.00)$, newscasts $(M=.61$, $S D=.48$; range $=0-2.00)$, weekday cartoons $(M=.81, S D=.52$; range $=0-2.00)$, and weekend cartoons $(M=.86, S D=.45$; range $=0-2.00)$. Tests for gender differences on the independent variables showed only that boys reported significantly higher sensation seeking than girls $F(1,60)=4.73, p<.03$ (means $=4.41$ and 3.07 for males and females respectively). The overall pattern of means and gender differences found here is consistent with previous research examining children's injury behaviors and sensation seeking (e.g., Potts et al., 1995).

\section{Risk Appraisal Domains}

A summary risk appraisal score for each domain (child, adult, and TV) was created by summing the scores $(1=$ "definitely will not get hurt" to $5=$ "definitely will get hurt") for each of the 5 items within the domain and dividing by 5 . The mean risk appraisal scores were all at the moderately risky level: child risk situations $M=3.17(S D=.71)$; adult risk situations $M=3.00(S D=.65)$, and TV risk situations $M=3.85(S D=.50)$.

To examine the consistency of risk appraisal scores across the three risk domains, a 3 (risk domain) $\times 2($ sex $) \times 2$ (grade) repeated measures analysis of variance was conducted, with risk appraisal in the three domains serving as the dependent variable. Only risk domain was a significant factor, $F(2,115)=40.51, p<.001$; no other factor or interaction of factors was significant (all $p \mathrm{~s}>.10$ ). Follow-up analyses using simple effects comparisons indicated that subjects appraised the TV situations as more risky than either the child situations, $t(115)$ $=7.37, p<.001$, or the adult situations, $t(115)=-9.67, p<.001$. No significant difference was found between the risk appraisals of the child and adult situations. Risk appraisal scores 
on the three domains were only moderately interrelated. Scores for the TV and adult situations were modestly correlated, $r(62)=.26, p<.02$, as were those for the TV and child situations $r(62)=.20, p<.05$; scores for the child and adult situations were not related. These collective results indicate that, in general, subjects differentiated between the child, adult, and television risk appraisal domains, and did not judge them in a similar way.

After making these risk appraisals, children's direct experience was measured by asking them to indicate how often they had performed the behaviors represented in the stimulus situations. As mentioned previously, the risk appraisal items were chosen largely upon expected levels of children's direct experience with child, adult, and TV-like activities. Results confirm these choices as children reported mean direct experience scores of 1.02 $(S D=.42)$ for the child risk situations, and $.08(S D=.14)$ for the adult risk situations; no child reported any direct experience with any of the TV risk situations.

\section{Predictors of Risk Appraisal}

Because risk appraisal was found to be relatively domain-specific, separate regression analyses were conducted for each risk domain appraisal score. Predictor variables included child gender, age, sensation seeking, injury history, IBC score, direct experience scores, and the home television viewing categories. The order of entry of independent variables into the regression equations was guided by Hyson and Bollin's (1990) theoretical categories of risk taking predictors. Sex, age, and sensation seeking, which represented the most fundamental subject variables measured here, were allowed to enter first, in a single block, followed by those reflecting first-hand experience with physical risk-taking (injury history, IBC score, and direct experience scores); the last block included tele-

Table 2. Summary of Hierarchical Regression Results for Child, Adult, and Television Risk Appraisals

Risk Domain

\begin{tabular}{lccc} 
Predictor & Child & Adult & Television \\
\hline Age (1) & $\mathrm{ns}$ & $-.290^{*}$ & $\mathrm{~ns}$ \\
Sensation seeking (1) & $\mathrm{ns}$ & $\mathrm{ns}$ & $-.312^{* *}$ \\
Sex (1) & $\mathrm{ns}$ & $\mathrm{ns}$ & $\mathrm{ns}$ \\
IBC (2) & $\mathrm{ns}$ & $\mathrm{ns}$ & $\mathrm{ns}$ \\
Injury history (2) & $\mathrm{ns}$ & $\mathrm{ns}$ & $-.300^{* *}$ \\
Direct experience (2) & $-.316^{*}$ & $\mathrm{~ns}$ & - \\
Action programs (3) & $\mathrm{ns}$ & $\mathrm{ns}$ & $\mathrm{ns}$ \\
News programs (3) & $\mathrm{ns}$ & $\mathrm{ns}$ & $\mathrm{ns}$ \\
Sports programs (3) & $\mathrm{ns}$ & $\mathrm{ns}$ & $\mathrm{ns}$ \\
Weekday cartoons (3) & $\mathrm{ns}$ & $\mathrm{ns}$ & $-.280^{*}$ \\
Weekend cartoons (3) & $\mathrm{ns}$ & $\mathrm{ns}$ & $\mathrm{ns}$ \\
Final equation & $R^{2}=.10, p<.01$. & $R^{2}=.08, p<.02$. & $R^{2}=.12, p<.05$. \\
\hline
\end{tabular}

Notes: Table entries are beta weights. Numbers in predictor column refer to order of entry into equation; within each entry group variables were allowed to enter stepwise, thus final equations include only significant predictors. Direct experience variable not included in analysis of television risk appraisal (see text).

$*=p<.05$.

$* *=p<.01$. 
vision viewing variables, which were assumed to reflect primarily indirect exposure or vicarious experience with risk taking. Thus, the regression was hierarchical over blocks, but stepwise within blocks.

Presented in Table 2 are results of the three regression analyses. For the measure of risk appraisal of child situations, direct experience with those situations was the single predictor to enter the equation, indicating that the more child risk behaviors subjects had directly experienced, the lower their risk appraisals were of those situations. For the measure of risk appraisal of adult situations, age was the single significant predictor to enter the equation. Older subjects tended to appraise the adult situations as less risky than younger subjects did. For the measure of appraisal of TV risk situations, the predictor variables of sensation seeking, injury history, and weekday cartoon viewing all entered the equation and all were in a negative direction. This indicated that high sensation seeking was associated with lower risk appraisals, more frequent injuries were associated with lower risk appraisals, and frequent weekday cartoon viewing was associated with lower risk appraisals.

\section{DISCUSSION}

This study furthers current knowledge of children's appraisals of physical risks. In general, results support Hyson and Bollin's (1990) proposition that a variety of factors (developmental, personality, and social) may influence children's estimates of risk consequences. Findings that each domain of risk appraisal was predicted by different factors or combinations of factors also expand their framework, suggesting that risk appraisal might best be conceptualized as domain-specific rather than as a global construct. Means comparisons and modest intercorrelations among the three risk domains lend additional support to the apparent multidimensionality of risk appraisal. Children's ratings of the TV situations as most dangerous may have reflected actual differences in hazard levels among the three risk domains. However, this finding also underscores the importance of children's own direct experience when evaluating childhood injuries. Children viewed risk situations that they might actually be exposed to in a very different way than risk exposures they are unlikely to encounter (e.g., working underneath a car or in a ninja fight on television). These results are consistent with previous empirical evidence (Slavic, 1987), as well as social learning principles which maintain that expectations about behaviors and their consequences are often learned in a situation-specific manner (Bandura, 1986).

Many of the independent variables measured were related to risk appraisal in ways consistent with previous research and theoretical predictions. Prior participation in the child risk situations resulted in children underestimating risk (relative to their peers) in those same situations. This is consistent with Horvath and Zuckerman's (1993) findings that low risk appraisal is related to high risk taking, and that risk appraisal may be a consequence rather than a cause of risky behavior. In other words, past risks not accompanied by injury may have delimited children's risk appraisals. Evidence suggests that successful performance of a risky behavior without being injured may lead to lower risk appraisals of similar situations in the future.

Age was strongly and negatively related to risk appraisal of the adult situations. With increased age, children perceived situations as having less risk involved. This coincides with other studies reporting age-related decreases in risk appraisals (Peterson et al., 1994; 
Peterson et al., 1997). Compared to younger children, older children are likely to possess greater knowledge of the adult occupational world as represented in the adult risk stimuli. With this increased familiarity, they may realize that even risky adult occupations are commonly performed with a relatively low occurrence of injury, and thus they perceive less risk in those situations.

Weekday cartoon viewing was predictably and significantly related to appraisal of the television items. Those children who viewed more weekday cartoons judged the TV situations to be less dangerous than children who viewed such programs less frequently. This finding is congruent with results of television content analyses (Potts \& Henderson, 1991) which showed that TV programs produced for child audiences typically depict few serious consequences of risky behaviors. Through social learning processes (Bandura, 1986) children who frequently view cartoons, and thus only minor consequences of injury behaviors, are likely to internalize such beliefs, and therefore report lower risk appraisals of similar situations. The influences of television viewing may be less apparent for appraisal of more mundane everyday situations, ones with which children have a greater amount of direct personal experience.

As expected, sensation seeking significantly predicted risk appraisals, but only in the television domain. With increases in sensation seeking, children tended to view the TV situations as being less risky. These results are consistent with those of Zuckerman (1979), who found that sensation seeking was negatively related to risk appraisal of novel situations in adults. In this study, direct experience scores from the children indicate that the TV scenarios were more novel than the other domains.

Finally, more extensive injury histories were linked to lower risk appraisals, but only of the television situations. Children with more prior injuries perceived less risk, even in the improbable and quite perilous TV situations. Again, this supports the likelihood that prior injury experiences may have a desensitizing effect upon children, leading to reduced estimations of future risk. This finding parallels those of the child and adult domains, in which broad indicators of exposure to injury and risk situations (i.e., direct experience and age) were also predictive of decreased risk appraisals.

Children who consistently underestimate the risk of injury in TV situations may place themselves at greater risk of real-world harm, through emulation of TV models. Thus, health educators should consider the benefits of media literacy curricula (e.g., Brown, 1986), designed to educate children about the fictitious and fabricated nature of entertainment television. Such training could help temper the undesirable effects of TV models upon children's behavior. In this case, children could be helped to distinguish between television and real-world injury risks.

No gender differences in risk appraisal were found here, despite previous findings that boys display higher levels of risk taking and experience more injuries than girls (Ginsburg \& Miller, 1982; Kafry, 1982; Matheny, 1991; Potts et al., 1994; Zuckerman, 1979), and that girls report greater fear and less exhilaration in response to hazards than boys (Peterson et al. 1997). This inconsistency between past and present findings calls into question the possibility of a direct causal link between lower risk appraisals and increased risk-taking behavior. It could be that boys and girls are similar in their estimations of risky situations, but due to differences in socialization, vary in their willingness to engage in risky behaviors in those situations. 
Several factors which limit the present study could be addressed in future research. First, causality cannot be concluded due to the correlational nature of this study. Second, because children responded to pictorial representations of risk situations, which are imperfect representations of real-life experiences, their affective reactions to the stimuli might have been diminished in comparison to actual risk situations. Laboratory procedures that simulate real-life risk situations have been devised (Cataldo et al., 1990), and could possibly be adapted for use in future studies of risk appraisal. Third, risk domains in this study were created a priori and included a total of only 15 items. Future research using a larger pool of risk situations grouped empirically, as well as conceptually, might yield more precise representations of risk domains. Finally, data collected from this sample, which consisted of mostly white, middle-class children from a small town, may not be generalizable to children with different sociodemographic characteristics, those for instance living in urban environments with objectively higher daily risks of injury.

Among adolescents, injury has been said to occur secondary to misinterpretations of risk (Tversky \& Kahneman, 1981). Similar processes may be at work in the age range studied here. When alone and confronted with hazardous situations, children's judgments of risk may influence their decisions whether to engage in injury-producing or injuryavoiding behaviors. Risk appraisals may even function in conjunction with other cognitive risk factors, such as overestimations of one's own physical abilities (e.g., Plume\& 1995), to contribute to injury. In some cases children's tendencies to misinterpret risks may simply reflect a lack of awareness of the dangers associated with certain behaviors. Knowledge regarding the determinants of risk appraisal can be helpful in targeting interventions for all children, especially those most at risk for physical harm because of distorted appraisals of environmental risks.

Acknowledgements: This research was supported by an APA Dissertation Research Award presented to the fist author. A previous version of this study was presented at the meeting of the American Psychological Association, Chicago, IL, August, 1997. The authors would like to acknowledge the helpful comments of Dr. Lizette Peterson on an earlier draft of this paper.

\section{REFERENCES}

American Psychological Association. (1992). Ethical principles of psychologists. American Psychologist, 47(12), 1597-1611.

Acredolo, C., O’Conner, J., Banks, L., \& Horobin, K. (1989). Children's ability to make probability estimates: Skills revealed through application of Anderson's functional measurement methodology. Child Development, 60, 933-945.

Bandura, A. (1986). Social foundations of thought and action: A social cognitive theory. Englewood Cliffs, NJ: Prentice Hall.

Brown, L. K. (1986). Taking advantage of media: A manual for parents and teachers. Boston: Routledge and Kegan-Paul.

Cataldo, M. F., Finney, J. W., Richman, G. S., Riley, A. W., Hook, R. J., Brophy, C. J., \& Nau, P. A. (1990). Behavior of injured and uninjured children and their parents in a simulated hazardous setting. Journal of Pediatric Psychology, 17, 73-80. 
Center for Research on the Influence of Television on Children (1983). CRITC Program Categorization System Coding Manual. Lawrence, KS: University of Kansas.

Cook, S., Peterson, L., \& DiLillo, D. (in press). Fear and exhilaration in response to risk: Correlates of injury in a real world context. Behavior Therapy.

Ginsburg, H. J., \& Miller, S. M. (1982). Sex differences in children's risk-taking behavior. Child Development, 53, 426-428.

Hollingshead, A. B. (1957). Two Factor Index of Social Position Unpublished manuscript, Yale University, New Haven, CT.

Horvath, P., \& Zuckerman, M. (1993). Sensation seeking, risk appraisal, and risky behavior. Personality and Individual Differences, 14, 41-52.

Huston, A., Donnerstein, E., Fairchild, H., Feshbach, N., Katz, P., Murray, J., Rubinstein, E., Wilcox, B., \& Zuckerman, D. (1992). Big world, small screen: The role of television in American society. Lincoln, NE: University of Nebraska Press.

Hyson, M. C., \& Bollin, G. G. (1990). Children's appraisal of home and neighborhood risks Questions for the 1990s. Children's Environments Quarterly, 7, 50-60.

Jaquess, D. L., \& Finney, J. W. (1994). Previous injuries and behavior problems predict children's injuries. Journal of Pediatric Psychology, 19, 79-89.

Kafry, D. (1982). Sensation seeking of young children. Personality and Individual Differences, $3,161-166$.

Matheny, A. P., Jr. (1991). Children's unintentional injuries and gender: Differentiation by environmental and psychosocial aspects. Children's Environments Quarterly, 8, 51-61.

Miller, D. C., \& Byrnes, J. P. (1997). The role of contextual and personal factors in children's risk taking. Developmental Psychology, 33, 814-823.

National Academy of Sciences. (1985). Injury to America: A continuing public health problem. Washington, DC: National Academy Press.

Peterson, L., Brazeal, T., Oliver, K., \& Bull, C. (1997). Gender and developmental patterns of affect, belief, and behaviors in simulated injury events. Journal of Applied Developmental Psychology, 18, 531-546.

Peterson, L., Gillies, R., Cook, S. C., Schick, B., \& Little, T. (1994). Developmental patterns of expected consequences for simulated bicycle injury events. Health Psychology, 13(3), 218223.

Peterson, L., Moreno, A., \& Harbeck-Weber, C. (1993). “And then it started bleeding”: Children's and mothers' perceptions and recollections of daily injury events. Journal of Clinical Child Psychology, 22, 345-354.

Plumert, J. M. (1995). Relations between children's overestimations of their physical abilities and accident proneness. Developmental Psychology, 31, 866-876.

Potts, R., Doppler, M., \& Hernandez, M. (1994). Effects of television content on physical risk-taking in children. Journal of Experimental Child Psychology, 58, 321-331.

Potts, R., \& Henderson, J. (1991). The dangerous world of television: A content analysis of physical injuries in children's television programming. Children's Environments Quarterly, 8, 7- 14.

Potts, R., \& Martinez, I. G. (1994). Television viewing and children's beliefs about scientists. Journal of Applied Developmental Psychology, 15, 287-300. 
Potts, R., Martinez, I. G., \& Dedmon, A. (1995). Childhood injury and risk-taking: Self-report and informant measures. Journal of Pediatric Psychology, 20, 661-668.

Potts, R., Martinez, I. G., Dedmon, A., Schwarz, L., DiLillo, D. K., \& Swisher, L. (1997). Brief report: Cross-validation of the Injury Behavior Checklist in a school-age sample. Journal of Pediatric Psychology, 22,533-540.

Rice, D. B., \& Mackenzie, E. J. (1989). Cost of injury in the United States: A report to Congress 1989. San Francisco: University of California Institute for Health and Aging.

Rodriguez, J. G. (1990). Childhood injuries in the United States: A priority issue. American Journal of Diseases of Children, 144, 625-626.

Ross, E., Wartella, E., \& Lovelace, V. (1982). A conceptual framework for describing children's television viewing patterns. Paper presented at the Southwestern Society for Research in Human Development, Galveston, TX

Routh, D. K. (1997). Injury control research in pediatric psychology: A commentary and a proposal. Journal of Pediatric Psychology, 22, 495-498.

Russo, M. F., Lahey, B., Christ, M., Frick, P., McBurnett, K., Walker, J., Loeber, R., StouthamerLoeber, M., \& Green, S. (1991). Preliminary development of a sensation seeking scale for children. Personality and Individual Differences, 12, 399-405.

Russo, M. F., Stokes, G. S., Lahey, B. B., Christ, M., McBurnett, K. M., Loeber, R., StouthamerLoeber, M., Green, S. M. (1993). A sensation seeking scale for children: Further refinement and psychometric development. Journal of Psychopathology and Behavioral Assessment, 15, 6986.

Slavic, P. (1987). Perception of risk. Science, 236, 280-285.

Speltz, M. L., Gonzales, N., Sulzbacher, S., \& Quan, L. (1990). Assessment of injury risk in young children: A preliminary study of the Injury Behavior Checklist. Journal of Pediatric Psychology, 15, 373-383.

Spielberger, C. D., \&Frank, R. G. (1992). Injury control: A promising field for psychologists. American Psychologist, 47, 1029-1030.

Tangney, J. P. (1988). Aspects of the family and children's television viewing content preferences. Child Development, 59, 1070-1079.

Tversky, A., \& Kahneman, D. (1981). The framing of decisions and the psychology of choice. Science, 211, 453-458.

Valsiner, J. (1985). Theoretical issues of child development and the problem of accident prevention. In T. Garling \& J. Valsiner (Eds.), Children within Environments: Toward a psychology of accident prevention (pp. 13-36). New York: Plenum.

Walesa, C. W. (1977). Development of risk perception in children and adolescents. Polish Psychological Bulletin, 8, 171-176.

Zuckerman, M. (1979). Sensation seeking and risk taking. In C. E. Izard (Ed.), Emotions in personality and psychopathology (pp. 163-197). New York: Plenum.

Zuckerman, M. (1994). Behavioral expressions and biosocial bases of sensation seeking. New York: Cambridge University Press. 